\title{
UM ESTUDO SOBRE A UTILIZAÇÃO DE ESPAÇOS NÃO FORMAIS PELAS ESCOLAS ESTADUAIS DE ENSINO MÉDIO DA CIDADE DE UBERABA/MG*
}

Carla Madalena Santos Monica Izilda da Silva

\section{Introdução}

Os conhecimentos imprescindíveis à vida cotidiana nem sempre são aprendidos formalmente nas disciplinas escolares. No processo de construção de conhecimentos, os espaços não formais de educação ganham relevância.

De acordo com Gaspar (2002), a educação pode ser compreendida como a capacidade de desenvolvimento intelectual da criança e dos homens, sendo um processo amplo e abrangente, quase sempre associado à escola. No entanto, devido ao tempo e ao currículo limitados e associados à educação formal, a escola por vezes tem apresentado dificuldades em difundir todo o conhecimento científico e tecnológico que tem sido produzido através dos tempos. Por esse motivo a aproximação com a educação não formal pode contribuir com aquilo que a escola não consegue oferecer.

Nesse sentido, Gohn (2006) destaca que a educação não formal é importante por considerar o ser humano na sua totalidade, contribuindo com a educação formal. A educação não formal possui objetivos próprios, os quais podem privilegiar aspectos não contemplados pela educação formal. Em destaque, citamos: a educação para a cidadania, para os direitos humanos, para a liberdade, para a democracia, pelo

*DOI - 10.29388/978-65-86678-24-6-0-f.57-76 
exercício da cultura e para a manifestação das diferenças culturais. Percebemos que as ideias de Gohn (2006) dialogam com o objetivo da interdisciplinaridade proposta por Luck (1997, p. 60), ao afirmar a busca por "promover a superação da visão restrita de mundo e a compreensão da complexidade da realidade e na produção do conhecimento, de modo permitir ao mesmo tempo uma melhor compreensão da realidade e do homem como ser determinado e determinante".

Para alcançarmos os objetivos propostos em um trabalho interdisciplinar e a utilização de espaços não formais de educação, percebemos a necessidade de uma transformação profunda em aspectos pedagógicos e, em uma nova abordagem de formação docente, como citado por Fazenda (2011, p. 48-49), ao afirmar que:

Passa-se de uma relação pedagógica baseada na transmissão do saber de uma disciplina ou matéria - que se estabelece segundo um modelo hierárquico linear - a uma relação pedagógica dialógica na qual a posição de um é a posição de todos. Nesses termos, o professor passa a ser $o$ atuante, $o$ crítico, $o$ animador por excelência.

Complementando essa ideia, Marandino (2015) defende que os cursos voltados à formação de professores devem apresentar discussões sobre o processo de ensino e aprendizagem que ocorrem em espaços não formais de educação, considerando a possibilidade de utilização desses espaços pelos futuros professores, quando em atuação nas escolas. Nessa mesma vertente, Jacobucci (2008) aponta que pesquisadores da área de Educação, profissionais de divulgação científica e professores de diversas áreas do conhecimento têm utilizado a educação não formal para descrever lugares onde é possível desenvolver atividades educativas que promovam um aprendizado mais contextualizado. Acrescenta, ainda, o potencial educacional destes espaços, a exemplo de centros de ciências, para a divulgação científica. Dessa forma, considerando esta breve introdução, listamos como objetivos deste texto: 
- Identificar quais os principais espaços não formais de educação que são utilizados pelos professores do Ensino Médio da Cidade de Uberaba, Minas Gerais;

- Verificar a possibilidade do desenvolvimento do trabalho interdisciplinar nestes ambientes;

- Investigar se os professores dessa rede pública de ensino foram preparados para trabalharem nesses espaços.

Como procedimento metodológico, realizamos uma pesquisa qualitativa, com análise das respostas apresentadas pelos professores aos questionários enviados para todas as escolas estaduais de Ensino Médio da cidade de Uberaba/MG, em julho de 2018. Para a análise dos achados da pesquisa utilizamos a Análise de Conteúdo, segundo Bardin (1977). Escolhemos trabalhar com escolas de Ensino Médio porque as orientações curriculares para essa etapa de escolarização, as Orientações Curriculares para o Ensino Médio (BRASIL, 1996), preveem a importância da utilização de espaços que vão além da sala de aula no processo de ensino e aprendizagem dos alunos, podendo o professor propor atividades interdisciplinares e o aprofundamento das atividades desenvolvidas ao longo da educação básica.

\section{Desafios e possibilidades para a utilização de espaços não formais de educação no processo educativo}

O entendimento da educação como processo de desenvolvimento intelectual do sujeito geralmente está associado à escola. Gaspar (2002) ressalta que a estrutura organizacional, que consta de cursos, níveis, horários, currículos, diplomas e conteúdos separados por áreas, não é recente e caracteriza a educação formal. Essas ideias dialogam com as apresentadas por Gohn (2006, p. 26), ao afirmar que "a educação formal pressupõe ambientes normatizados, com regras e padrões comportamentais definidos previamente".

Levando em consideração a dinamicidade da sociedade e das 
ideias, o processo educativo também precisa se recriar em outros espaços que não sejam apenas os espaços formais escolares. Assim os espaços não formais podem surgir como travessias para um processo que provoque sentidos no processo ensino-aprendizagem dos educandos. No ambiente não formal, confere-se a socialização do indivíduo e o desenvolvimento de hábitos e atitudes a partir da vivência. A este despeito Gohn (2006, p. 30) acentua que:

$\mathrm{Na}$ educação formal espera-se, sobretudo, que haja uma aprendizagem efetiva (que, infelizmente nem sempre ocorre), além da certificação e titulação que capacitam os indivíduos a seguir para graus mais avançados. Na educação não formal os resultados não são esperados, eles simplesmente acontecem a partir do desenvolvimento do senso comum nos indivíduos, senso este que orienta suas formas de pensar e agir espontaneamente.

Nesse ponto de vista, percebemos que há tempos a escola perdeu o monopólio da educação, como defendem Lombana, Delgado e Giraldo (2013). A ideia apresentada anteriormente complementa o raciocínio de Gaspar (2002), no que diz respeito à educação não formal. Ao caracterizá-la, ela destaca sua ocorrência em lugares, horários ou currículos não definidos, marcados pela espontaneidade e inconsciência, podendo acontecer em centros culturais, jardins botânicos, zoológicos, museus de arte e ciências, ou seja, em qualquer terreno onde saberes e artes possam ser partilhados, podendo caracterizar ambientes nos quais a aprendizagem acontece.

Gaspar (2002) e Ovigli (2013, p. 31) dialogam no âmbito da valorização do processo educativo que emanam nos espaços que extrapolam os muros da escola e que reduzem a "distância entre os avanços da Ciência e Tecnologia e o currículo escolar". As concepções apresentadas por Gaspar (2002), Gohn (2006) e Ovigli (2013) são complemen tadas por Falk e Dierking (2010) no que diz respeito à educação em espaços não formais. Nesse sentido, sem diminuir a importância da educação formal, esses autores ressaltam o valor do processo educativo 
nos espaços não formais, como ambientes ricos para o processo de ensino e aprendizagem.

Muitos educadores trazem consigo inquietações e dúvidas quanto ao ensino de ciências em espaços não formais ao considerarem que esses espaços são destinados ao lazer e questionam seu potencial educativo. Gaspar (2002) aponta que, devido ao alto grau de dispersão dos alunos nesses ambientes, educadores não acreditam na possibilidade de compreensão de conteúdos científicos abstratos, sem um ordenamento lógico rígido, deixando assim de explorarem os espaços não formais. $\mathrm{O}$ mesmo autor, porém, destaca a existência de inúmeras pesquisas acadêmicas realizadas em centros de ciências, em todo o mundo, atestando que muitos conceitos científicos se tornam mais bem compreendidos depois de uma visita a um centro de ciências.

Nesta vertente, compartilhamos das ideias de Marandino (2003), para quem trabalhar durante a formação inicial do professor a relação entre os ambientes não formais de educação e os espaços formais (escolares) pode ser um caminho promissor para fortalecer e ampliar a construção de itinerários formativos.

\section{Museu e escola: uma parceria que pode contribuir para o processo educativo interdisciplinar}

A realidade das escolas brasileiras tem evidenciado uma educação marcada, historicamente, por currículos fragmentados e desarticulados. As disciplinas são organizadas no currículo em forma de "grades estanques", não apresentando relação com a vida do educando, o que dificulta sua aprendizagem e reforça a postura de aluno por vezes passivo, repetidor fiel dos ensinamentos do professor.

Gerhard e Rocha Filho (2012, p. 127) expõem que “[...] a fragmentação do conhecimento científico a ser ensinado manifesta-se na separação das disciplinas na escola e tem sido danosa para a educação". Trata-se de uma constatação que incomoda e revela a necessidade de novos olhares para a questão, quem sabe com as lentes de um 
trabalho interdisciplinar. É fato que muitos alunos entendem a ciência ensinada nas escolas como ultrapassada e desmotivadora (COLOMBO JUNIOR, 2014). Segundo Colombo Junior (2014), os centros de ciências são locais que o professor dispõe na sociedade para ampliar as possibilidades formativas e de aprendizagem dos alunos. Desta forma, o autor defende a necessidade de incluir nos planejamentos anuais dos professores de Ciências, em especial, atividades em espaços não formais de educação. O aluno, ao se deparar com a Ciência em um ambiente diferente das salas de aula, pode começar a interpretá-la como mais interessante, desafiadora e motivadora.

Assim entendemos que os museus, em geral, podem ser concebidos como espaços de experiências enriquecedoras de aprendizagem e socialização constituindo, assim, valiosos recursos educacionais. Lombana, Delgado e Giraldo (2013) deixam evidente a função educativa dos museus quando demonstram que esses espaços, nos últimos anos, tornaram-se centros de interpretação e reflexão sobre a sociedade contemporânea, além da mudança de concepção desses cenários de função de lazer e entretenimento para espaços que colocam o conhecimento científico em jogo.

Nesse sentido percebemos que a aproximação entre museus e escolas pode ampliar os aspectos educativos, culturais e de comunicação presentes nos processos de ensino e aprendizagem de ciências. Da percepção que os responsáveis pelos museus têm da cooperação com a escola, destaca-se o diálogo horizontal na busca por objetivos comuns, os processos educativos. Entretanto, a relação em questão também apresenta problemas: Mora (2013) cita a falta de envolvimento do professor durante visitas didáticas aos espaços museais, além de estudantes se comportarem indevidamente durante as visitas. Por outro lado, a escola queixa-se da perda de aulas, da restrição de circulação de alunos em certas áreas do museu e da não retomada, em sala de aula, dos conhecimentos trabalhados no espaço, durante a visita.

Segundo Marandino (2003, p. 1) "existe um consenso com relação à importância e necessidade de se elaborar políticas e estratégias 
pedagógicas que efetivamente auxiliem na compreensão do conhecimento científico, por meio de experiências fora da escola”. Segundo Bitter (2009, p. 22):

Os museus têm se transformado profundamente desde sua criação [...]. Existem muitas maneiras de definir os museus, mas todas concordam com a definição abrangente estabelecida pelo Conselho Internacional de Museus (ICOM) de que se trata de instituições de interesse público com a finalidade de conservar, estudar, expor e valorizar os testemunhos materiais do homem e de seu ambiente, para educação e lazer da sociedade. Partindo dessa definição, são considerados museus: aquários, jardins zoológicos e botânicos, sítios e monumentos naturais e arqueológicos, centros de ciência e cultura que abrigam acervos, galerias de arte, exposições não comerciais, entre outras tantas.

Sendo assim os museus podem ser caracterizados como espaços que possuem diferentes finalidades, que incluem a divulgação científica, e que promovem possibilidades de aprendizagem e alfabetização científica, além de possibilitarem discussões de interface entre Ciência, Tecnologia e Sociedade.

\section{Percurso Metodológico}

Nosso percurso metodológico incluiu a aplicação de um formulário online, operacionalizado por meio do Google Formulários enviados aos professores das 22 escolas estaduais existentes da cidade de Uberaba/MG que oferecem o Ensino Médio e totalizam, segundo dados do Simade/2019, em torno de 700 professores. O formulário online envolveu questões como o nome do(a) professor(a), a(s) escola(s) que atua(m), habilitação, o que eles (elas) entendiam por espaços não formais, se trabalhavam ou não com espaços não formais em suas aulas e a justificativa para tal, bem como se a escola realiza projetos interdisciplinares. O primeiro movimento foi investigar o que os professo- 
res entendiam por espaços não formais de educação e em quais deles entendiam ocorrerem processos educativos. Obtivemos o retorno de 60 respostas de professores de diferentes áreas do conhecimento, escolas e realidades.

A presente pesquisa é, portanto, de natureza qualitativa, dada sua riqueza em detalhes (BOGDAN e BIKLEN, 1994). Analiticamente, adotamos como forma de olhar para os dados as ideias da Análise de Conteúdo a qual, de acordo com Bardin (1977), transcende as informações apuradas e busca decifrar os "significados" das respostas. Esta perspectiva "procura conhecer aquilo que está por trás das palavras sobre as quais se debruça" (BARDIN, 1977, p. 44). A perspectiva de análise de Bardin (1977) pressupõe três fases: pré-análise, exploração do material e tratamento de resultados. A pré-análise foi uma etapa que teve como objetivo a organização do material levantado junto aos professores, seguido da "leitura flutuante" de todo o corpus de dados. A exploração do material representa uma etapa mais longa, agregada à construção de categorias de análise, derivadas dos materiais analisados. As categorias foram elaboradas a partir da utilização de uma seção recortada de conteúdos, a qual denominamos de unidades de registro. Bardin (1977) cita como unidade de registros as palavras, o tema, o objeto ou o referente, o personagem, o acontecimento e o documento. Após a definição da unidade de análise, iniciamos a categorização. Por fim, no tratamento e na interpretação dos resultados, organizamos o cruzamento de informações obtidas por meio da análise integral das respostas recebidas.

Ao examinarmos os 60 questionários respondidos pelos professores, foi possível identificar as ações educativas que possibilitaram responder nossa questão norteadora: Quais espaços não formais de educação os professores do Ensino Médio têm utilizado para enriquecer o processo educativo em Uberaba/MG? Guiando nossas discussões, a partir da análise dos resultados obtidos, construímos a categoria de análise "espaços de educação formal e de educação não formal", e congregou: (i) espaços formais e não formais de educação, (ii) espa- 
ços não formais institucionais de educação e (iii) espaços não formais não institucionais.

\section{Resultados}

\section{Espaços de educação formal e de educação não formal}

Fazendo um panorama das respostas enunciadas pelos professores, conseguimos traçar um perfil dos participantes. É oportuno destacar, no entanto, que as análises dos dados evidenciaram um retorno maior de respostas dos professores com formação na área de Letras, conforme figura a seguir (Figura 1).

Figura 1. Número de Professores que participaram da pesquisa, por área de formação

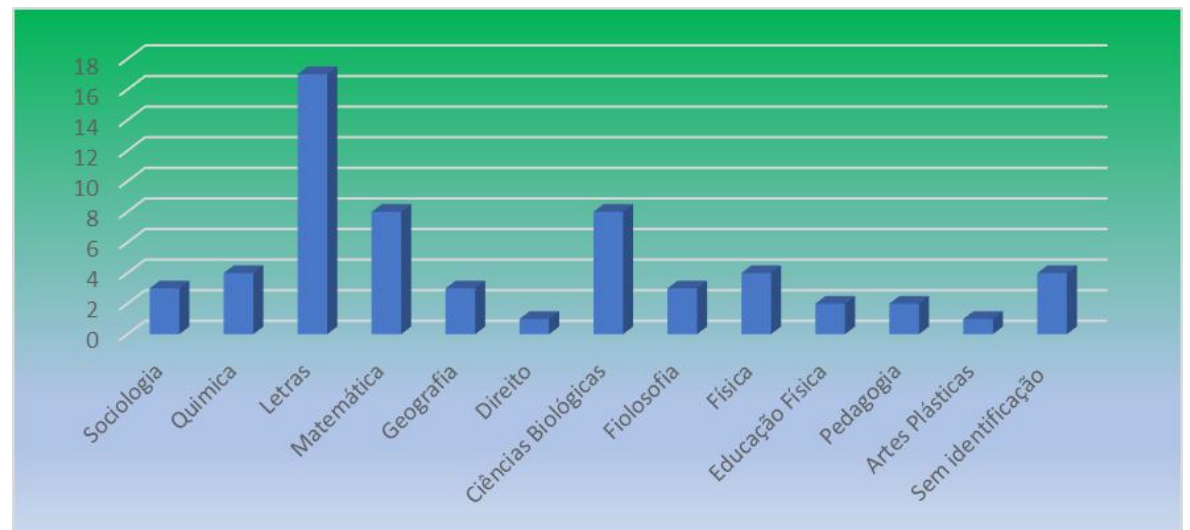

Fonte: autoras (2018)

A utilização dos espaços não formais de educação foi mencionada majoritariamente por professores da área de Letras, conforme demonstra o gráfico a seguir (Figura 2), o que nos leva a inferir que um número significativo de professores de outras áreas não têm desenvolvido atividades nestes ambientes. 
Figura 2: Utilização de espaços não formais de educação por áreas do conhecimento

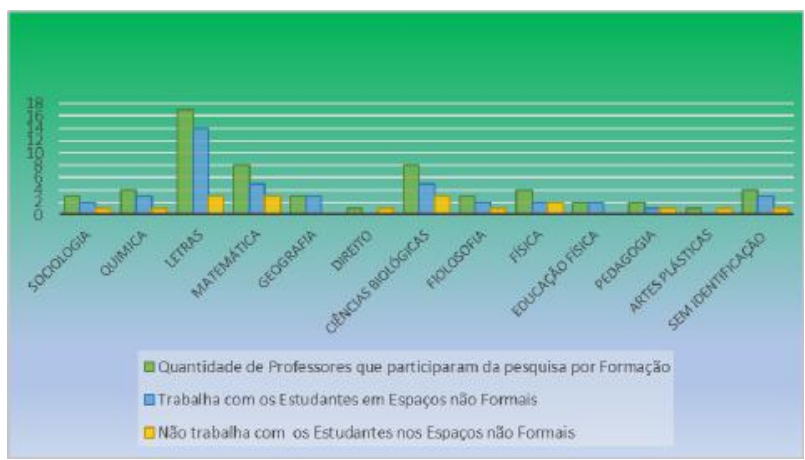

Fonte: autoras (2018)

Dos dados anteriores, percebemos que professores de diversas disciplinas utilizam, mesmo que de forma tímida, os espaços de educação não formal para desenvolvimento de atividades com os alunos. Comungou com Colombo Junior (2014, p. 25), que "estes espaços [de educação não formal] podem desempenhar um papel importante no processo de ensino e aprendizagem, visto que [pode] criar o senso de maravilha que sustenta o desejo de aprender". A percepção dos 60 professores pesquisados quanto à definição da educação em espaços não formais foi sintetizada na Figura 3.

Figura 3. Percepção dos professores quanto à definição de "espaços não formais no processo educativo"

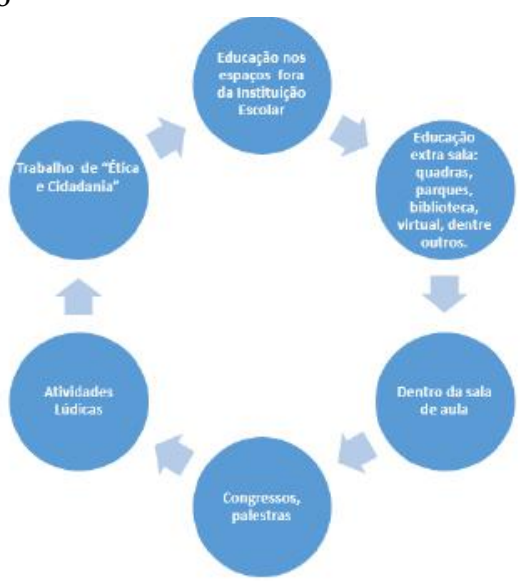

Fonte: autoras (2018) 
Analisando a percepção dos professores quanto à definição de "espaços não formais no processo educativo", notamos que 26 professores explicitaram uma definição para os espaços não formais de educação, respondendo: educação nos espaços fora da instituição escolar e educação extra sala: quadra, parques, biblioteca, rua, museu virtual, dentre outros. Embora estudos apontem uma variedade de definições para os termos educação formal e educação não formal, acreditamos que essas concepções dialogam com a definição apresentada por Colombo Junior (2014, p. 25-26) que menciona:

[...] podemos entender educação formal como aquela que está hierarquicamente estruturada em um sistema de educação cronologicamente graduado, incluindo estudos acadêmicos e uma variedade de programas especializados em instituições oficiais. A educação não formal pauta-se em atividades organizadas fora do sistema formal de educação operando separadamente ou como parte de atividades mais amplas complementares que pretendem servir a clientes previamente identificados como aprendizes e possui objetivos de aprendizagem

Por outro lado, os resultados evidenciaram que 34 professores não possuem uma definição, mesmo que inicial, sobre o termo "educação não formal” e nem conseguem diferenciá-las da educação formal, fato que está evidenciado em respostas como "educação não formal acontece dentro da sala de aula, congressos e palestras”. Ovigli (2013, p. 55) sinaliza que, mesmo os museus formalizando ao longo da história um papel importante dentro do processo educativo, foi a partir das décadas de 1960 e 1970 que "[...] a visita ao museu de ciências passou a ser pensada como uma experiência diferente, especial, assumindo características próprias. Trata-se de uma nova forma de encarar a relação visitante/objeto, por meio de atividades educativas”. Tal reflexão dialoga com os resultados e desafios declarados pelos próprios professores, já que por décadas os museus se configuraram mais próximos da elite, distanciando-se das camadas populares da sociedade. 
Quando questionados: "Você, enquanto professor, trabalha com os seus estudantes em espaços não formais?”, verificamos que 18 professores declaram não utilizá-los no processo educativo, ao passo que 42 indicaram que utilizam, porém sem definir a frequência com que o fazem (Figura 4).

Figura 4. Porcentagem de professores que utilizam os espaços não formais no processo educativo

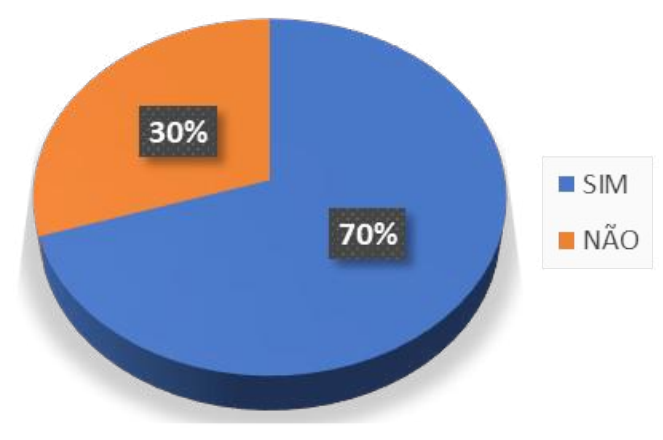

Fonte: autoras (2018)

Ao analisar o percentual de professores que não utilizam os es paços de educação não formal e o motivo para a não utilização, percebemos que o percentual que declara não utilizar é relativamente pequeno. Porém, dentre os professores que declararam utilizar, existem aqueles que desconhecem o conceito de educação não formal. Desta forma, inferimos que um número considerável de professores desenvolve atividades em ambientes formais acreditando estarem trabalhando em espaços não formais. Os motivos declarados pelos 18 respondentes para não utilizarem os espaços não formais para o processo educativo são apresentados na Figura 5. 
Figura 5. Motivos declarados pelos professores para não utilizarem os espaços não formais

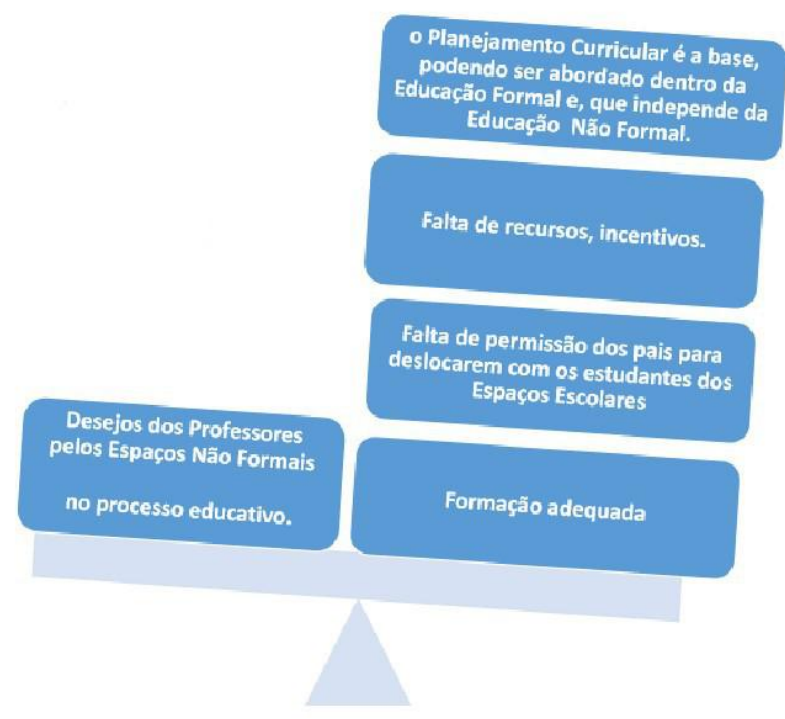

Fonte: autoras (2018)

Observando os motivos pelos quais os professores não utilizam espaços não formais de educação, consta que uma parcela deles desconhece que a utilização desses espaços pode oferecer contribuições importantes à educação formal. Segundo Abib e colaboradores (2012, p.1), "os museus e centros de Ciências promovem contribuições formativas aos professores nas diferentes áreas do conhecimento, o que revela o potencial desses espaços para mudanças no trabalho docente". Outro dado apurado em nossas análises refere-se aos projetos interdisciplinares que são desenvolvidos nas escolas. Apenas três professores mencionaram não conhecer projetos interdisciplinares realizados em suas escolas, no entanto nenhum professor mencionou visitas a ambientes de educação não formal dentre os projetos citados (Figura 6). 
Figura 6. Projetos interdisciplinares em desenvolvimento nas escolas

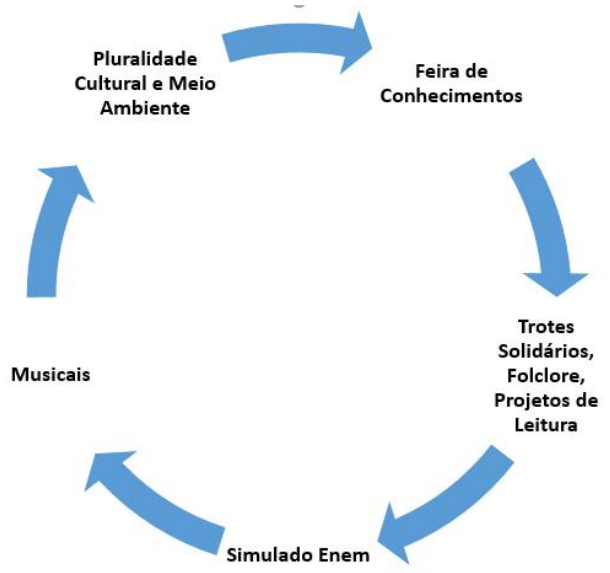

Fonte: autoras (2018)

Nossos resultados evidenciaram que, mesmo que $70 \%$ dos professores tenham declarado atuar com os seus estudantes em espaços não formais de educação, há um longo caminho a percorrer para que, de fato, estes espaços sejam valorizados pela comunidade escolar, para o desenvolvimento de atividades educativas e interdisciplinares. A ausência de clareza sobre o que são os espaços não formais de educação e, ainda, o que caracteriza um projeto como interdisciplinar é um desafio, sendo este um tema complexo não apenas para os professores, mas também para pesquisadores que se debruçam na busca por uma definição (JACOBUCCI, 2008).

Espaços formais de educação e espaços não formais de educação (institucionais e não institucionais)

Buscamos refletir sobre a distinção entre espaços formais e não formais de educação frente ao processo educativo, uma vez que um grupo de professores participantes explicitou o entendimento de espaços não formais como sinônimo de "sala de aula". Jacobucci (2008, p. 56) ressalta a definição dos espaços formais como sendo os que estão relacionados “[...] às Instituições Escolares da Educação Básica e do 
Ensino Superior, definidas na Lei 9394/96 de Diretrizes e Bases da Educação Nacional. É a escola, com todas as suas dependências: salas de aula, laboratórios, quadras de esportes, biblioteca, pátio, cantina, refeitório".

Os espaços educativos formais e não formais se completam quando são valorizadas todas as formas de interação propiciadas pelo processo educativo, dentro e fora do espaço escolar. Os espaços formais precisam ir além de moldes pré-fixados e engessados dentro das paredes da sala de aula, da atribuição de notas e de "grades curriculares” estanques. É preciso uma transposição de ações, para que de fato os espaços sejam espaços significativos indo ao encontro dos desejos e anseios dos estudantes.

No que se refere aos espaços não formais de educação, podemos dividi-los em institucionais e não institucionais. De acordo com Jacobucci (2008, p. 56-57) caracterizam-se como "espaços não formais institucionais de educação" aqueles normatizados sob as lentes de responsáveis técnicos, como: "museus, centros de ciências, parques ecológicos, parques zoobotânicos, jardins botânicos, planetários, institutos de pesquisa, aquários, zoológicos, dentre outros". Ao serem questionados sobre quais espaços de educação não formais os professores utilizavam como colaborativos ao processo ensino-aprendizagem dos alunos, os resultados foram dispersos, sendo representados nas Figuras 7 e 8 .

Figura 7. Espaços não formais institucionais de educação utilizados pelos professores

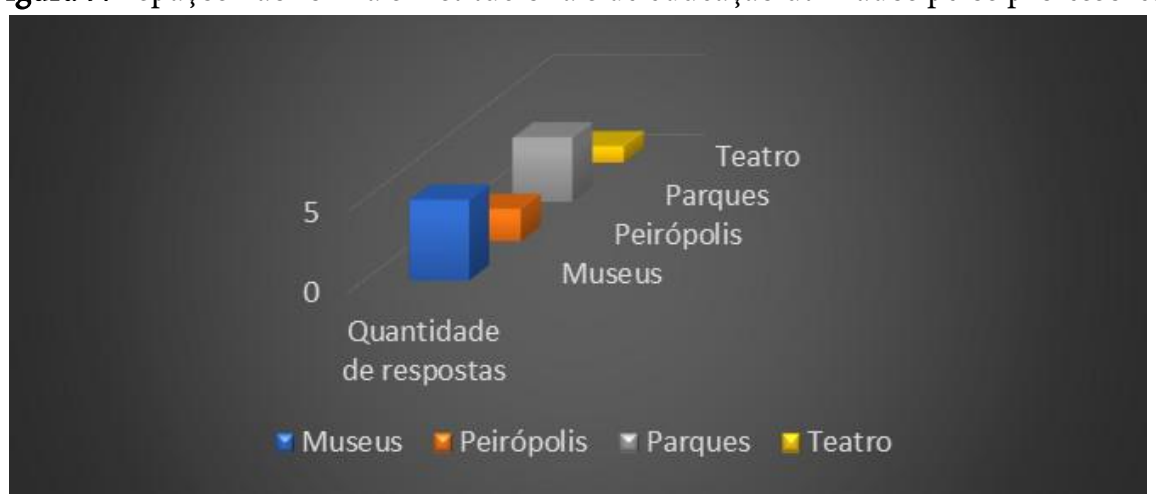

Fonte: autoras (2018) 
Os resultados nos levaram a concluir que há uma necessidade de maior conhecimento do potencial educativo do trabalho dos professores em espaços não formais institucionais de educação, uma vez que a participação neste questionamento foi reduzido, perfazendo 12 professores (20\% do total) que responderam a questão, sendo: Museus = 5; Peirópolis (Complexo Cultural e Científico situado em Uberaba) $=2$; Parques $=4$, e Teatro $=1$. Em oposição às respostas dos participantes, é oportuno destacar que a cidade de Uberaba/MG possui os seguintes museus: Museu de Arte Decorativa; Museu do Zebu; Museu de Arte Sacra; Casa de Memórias e Lembranças Chico Xavier; Memorial Chico Xavier, Museu dos Dinossauros, Museu da Vida e, Museu da Capela - Irmãs Dominicanas de Monteils. Gaspar (2002), Gohn (2006), Falk e Dierking (2010), Ovigli (2013), Colombo Junior (2014), sinalizam consenso ao defenderem a valorização destes espaços não formais institucionais para o processo de construção de um conhecimento significativo dentro do processo educativo, no qual estudantes e professores podem agregar valores e serem provocados pela curiosidade a partir de situações-problema.

Os “espaços não formais e não institucionais” são exemplificados por Jacobucci (2008, p. 56-57) como sendo teatros, parques, casas, ruas, praças, terrenos, cinemas, praias, cavernas, rios, lagoas, campos de futebol, dentre outros inúmeros espaços. São caracterizados "não institucionais e não formais" por se tratarem de espaços que não pertencem a espaços institucionalizados, mas sim a espaços "naturais e abertos”, não diminuindo a sua importância para a construção de uma aprendizagem significativa nestes espaços. Os "espaços não formais e não institucionais" utilizados pelos professores respondentes foram organizados conforme a Figura 8. 
Figura 8. Espaços não formais e não institucionais de educação utilizados pelos professores

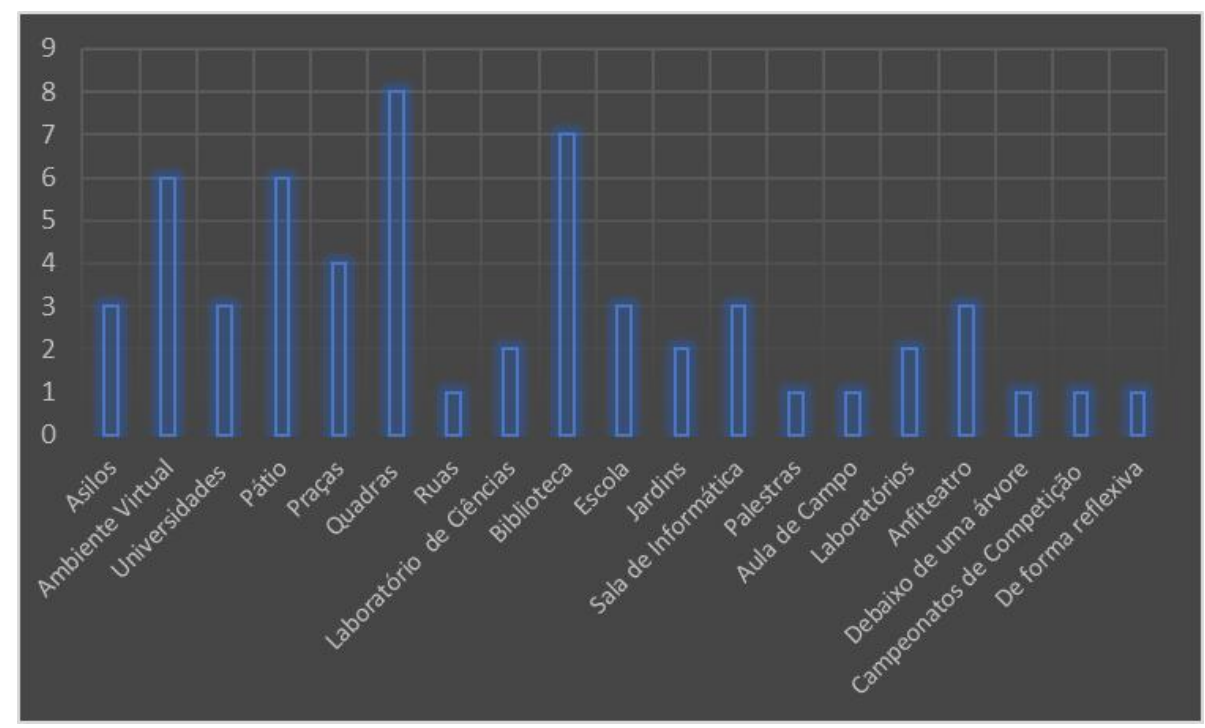

Fonte: autoras (2018)

Evidenciamos que a utilização dos espaços não formais, sejam eles institucionais ou não institucionais, vai ao encontro dos desafios enfrentados pelos professores quanto à ausência de recursos para oferecer aos estudantes a oportunidade de conhecer diferentes formas e espaços possíveis para o desenvolvimento dos processos de ensino e aprendizagem. Desta forma, entendemos que refletir e buscar meios para superar tais dificuldades é um caminho promissor para a aproximação entre a educação formal e a educação não formal e, quem sabe, para sair da famosa "dobradinha do giz e quadro", tão presentes nos dias atuais e rotina escolar, no sentido de valorizar o processo educativo em uma escola "sem paredes".

\section{Desfecho das análises realizadas}

A educação formal possui muitos valores, entretanto ela não pode ser considerada como a única forma de apropriação de conhecimentos. Toda experiência extraclasse deve ser considerada significati- 
va na apropriação de saberes socialmente construídos. Consequentemente, o cidadão mais bem informado aproveita melhor os benefícios da educação dentro e fora da escola. Nesse sentido, a educação formal e a educação não formal comungam para suprir estruturas cognitivas importantes que enriquecerão a capacidade de perceber e interpretar a si mesmo, seja por meio de experimentos que estimularão o diálogo em sala de aula (formal), seja em ambientes que possibilitem partilha de saberes entre todos que buscam conhecimento (não formal).

Em meio às análises realizadas, concluímos que os espaços mais utilizados pelos professores pesquisados no processo educativo com seus alunos são os espaços não formais institucionais, em especial as quadras das escolas. Um achado que nos leva a refletir que se faz necessário maior aproveitamento dos potenciais propiciados pelos diferentes espaços educativos, para além da escola, sejam eles de natureza formal, informal, institucional ou não. O potencial educativo dos museus foi retratado muito pouco pelos professores, apenas cinco mencionaram utilizar os espaços dos museus como aporte para o trabalho educativo com seus alunos, em um universo de 60. Desta forma, concluímos que os espaços não formais institucionais de educação têm sido subutilizados pelos professores como recursos pedagógicos.

Os dados da pesquisa indicam lacunas na formação desses professores em reconhecerem as possibilidades destes espaços como instrumentos que podem colaborar com um processo ensino-aprendizagem motivado pela curiosidade de quem os frequenta. Por fim, acreditamos que os espaços não formais, institucionais ou não, possuem capacidades que, somadas à sala de aula, contribuem imensamente para o processo de ensino e aprendizagem dos alunos.

\section{Referências}

BARDIN, L. Análise de conteúdo. Lisboa: Edições 70, 1977. 
BITTER, D. Museu como lugar de pesquisa. In: Museu e escola: educação formal e não formal. Salto para o Futuro. TV Escola. maio, 2009. p. 22 - 28. $39 \mathrm{p}$.

BRASIL. Ministério da Educação. Orientações curriculares para o Ensino Médio. Ciências da Natureza, Matemática e suas Tecnologias. Ministério da Educação - Educação Básica. 2006.

COLOMBO JUNIOR, P. D. Inovações curriculares em ensino de física moderna: investigando uma parceria entre professores e centro de ciências. 2014. 254f. Tese (Doutorado em Ensino de Física). Universidade de São Paulo, São Paulo, 2014. Disponível em: < $\underline{\text { http://www.teses.usp.br/teses/disponi- }}$ veis/81/81131/tde-04122014-141004/publico/Pedro_Donizete Colombo_Junior.pdf.> Acesso em: 04 mai. 2020.

FALK, J. H.; DIERKING, L. D. The 95 percent solution: school is not where most Americans learn most of their Science. American Scientist. Chapel Hill, v.98, p.485-93, nov./ dez. 2010.

. The contribution of free-choice learning to public understanding of science. INCI [online], v.27, n.2, p.62-65, 2002.

FAZENDA, I. Integração e interdisciplinaridade no ensino brasileiro: efetividade ou ideologia. 6 ed. São Paulo: Edições Loyola, 2011.

GASPAR, A. A educação formal e a educação informal em ciências. In: MASSARANI, L.; MOREIRA, I. C. (Orgs.). Ciência e público: caminhos da divulgação científica no Brasil. Rio de Janeiro: Casa da Ciência, Centro Cultural de Ciência e Tecnologia da Universidade Federal do Rio de Janeiro, 2002. p.171-83.

GERHARD, A.C.; ROCHA, F. J. B. A Fragmentação dos Saberes na Educação Científica Escolar na Percepção de Professores de uma Escola de Ensino Médio. Investigações em Ensino de Ciências, v.17, n. 01, p. 125-145, 2012.

GOHN, M. G. Educação não-formal, participação da sociedade civil e estruturas colegiadas nas escolas. Ensaio: aval. pol. públ. educ. Rio de Janeiro, v.14, n.50, p.27-38, jan./ mar. 2006.

JACOBUCCI, D. F. C. Contribuições dos Espaços não-formais de Educação para a Formação da Cultura Científica. Em Extensão, Uberlândia, v. 7, 2008. 
LOMBANA, C. A. S; DELGADO, F. A.; GIRALDO, N. A. B. Relaciones de Complementariedad MuseoEscuela: una mirada desde cuatro instituciones museísticas de medellín. : una mirada desde cuatro instituciones museísticas de Medellín. In: RÍOS, C. A. (ed.). El museo y la escuela: conversaciones del complemento. conversaciones del complemento. Medellín: Parque Explora, 2013. p. 53-64. Disponível em: <http://www.pedagogiademuseos.org/wpcontent/uploads/2013/08/Museo-Escuela-Libro-digital-Explora.pdf. $>$ cesso 25 mai. 2016.

LUCK, H. Pedagogia Interdisciplinar: fundamentos teórico-metodológicos. Petrópolis, Rio de Janeiro: Vozes, 1994.

MARANDINO, M. A prática de ensino nas licenciaturas e a pesquisa em ensino de ciências: questões atuais. Caderno Brasileiro de Ensino de Física, v. 20, n. 2, p.168-193, 2003.

. Educação Não Formal e Divulgação em Ciência: da produção do conhecimento a ações de formação / organizadores Martha Marandino e Djana Contier. São Paulo: Faculdade de Educação da USP, 2015. 106 p.

MORA, M. C. S. La relación museo-escuela: tres décadas de investigación educativa. In: RIOS, Claudia Aguirre (Org.). El museo y la escuela: converasiones de complemento. Sello Explora-Parque Explora: Medelim, 2013. p.15-22. Disponível em: $<$ http://www.pedagogiademuseos.org/wp-content/uploads/2013/08/Museo-Escuela-Libro-digital-Explora.pdf.> Acesso em: 03 mai. 2020.

OVIGLI, D. F. B. As pesquisas sobre educação em museus e centros de ciências no Brasil: estudo descritivo e analítico da produção acadêmica. 2013. 404 f. Tese (Doutorado em Educação para a Ciência) - Universidade Estadual Paulista Júlio de Mesquita Filho, Faculdade de Ciências, Bauru, 2013. 